\title{
Ex vivo susceptibility of Plasmodium falciparum isolates from Dakar, Senegal, to seven standard anti-malarial drugs
}

Bécaye Fall ${ }^{1}$, Silmane Diawara ${ }^{1}$, Kowry Sow ${ }^{1}$, Eric Baret ${ }^{2}$, Bakary Diatta ${ }^{3}$, Khadidiatou B Fall ${ }^{4}$, Pape S Mbaye , Fatou Fall ${ }^{6}$, Yaya Diémé ${ }^{\prime}$, Christophe Rogier ${ }^{2}$, Boubacar Wade ${ }^{7}$, Raymond Bercion ${ }^{1}$ and Bruno Pradines ${ }^{2,8^{*}}$

\begin{abstract}
Background: As a result of widespread chloroquine and sulphadoxine-pyrimethamine resistance, artemisinin-based combination therapy (ACT) (which includes artemether-lumefantrine and artesunate-amodiaquine) has been recommended as a first-line anti-malarial regimen in Senegal since 2006. Since then, there have been very few reports on the ex vivo susceptibility of Plasmodium falciparum to anti-malarial drugs. To examine whether parasite susceptibility has been affected by the widespread use of ACT, the ex vivo susceptibility of local isolates was assessed at the military hospital of Dakar.
\end{abstract}

Methods: The ex vivo susceptibility of 93 P. falciparum isolates from Dakar was successfully determined using the Plasmodium lactate dehydrogenase (pLDH) ELISA for the following drugs: chloroquine (CQ), quinine (QN), mefloquine (MQ), monodesethylamodiaquine (MDAQ), lumefantrine (LMF), dihydroartemisinin (DHA) and doxycycline (DOX).

Results: After transformation of the isolate $I C_{50}$ in ratio of $I C_{50}$ according to the susceptibility of the $3 D 7$ reference strain (isolate $I C_{50} / 3 D 7 I C_{50}$ ), the prevalence of the in vitro resistant isolates with reduced susceptibility was $50 \%$ for MQ, 22\% for CQ, 12\% for DOX, 6\% for both QN and MDAQ and 1\% for the drugs LMF and DHA. The highest significant positive correlations were shown between responses to CQ and MDAQ $(r=0.569 ; P<0.0001)$, LMF and QN $(r=0.511 ; P<0.0001)$, LMF and DHA $(r=0.428 ; P=0.0001)$, LMF and MQ $(r=0.413 ; P=0.0002)$, QN and DHA $(r=0.402 ; P=0.0003)$ and $\mathrm{QN}$ and $\mathrm{MQ}(r=0.421 ; P=0.0001)$.

Conclusions: The introduction of ACT in 2002 has not induced a decrease in $P$. falciparum susceptibility to the drugs DHA, MDAQ and LMF, which are common ACT components. However, the prevalence of $P$. falciparum isolates with reduced susceptibility has increased for both $\mathrm{MQ}$ and DOX. Taken together, these data suggest that intensive surveillance of the $P$. falciparum in vitro susceptibility to anti-malarial drugs in Senegal is required.

\section{Background}

During the past 20 years, many strains of Plasmodium falciparum have become resistant to chloroquine and other anti-malarial drugs [1]. The emergence and spread of drug-resistant parasites has generated an urgent need for the development of novel anti-malarial drugs. One strategy for reducing malaria prevalence is the use of

\footnotetext{
* Correspondence: bruno.pradines@free.fr

${ }^{2}$ Unité de parasitologie - Unité de recherche sur les maladies infectieuses et transmissibles émergentes - UMR 6236, Institut de recherche biomédicale des armées, Allée du Médecin-colonel Jamot, Parc le Pharo, BP 60109, 13262 Marseille Cedex 7, France

Full list of author information is available at the end of the article
}

drugs in combination. Drug combinations protect each component drug from the development of resistance and reduce the overall transmission of malaria [2]. Since 2001, more than 60 countries have officially adopted artemisinin-based combination therapy (ACT) for the treatment of falciparum malaria; moreover, ACT is now the official first-line treatment against malaria in Africa [3]. In ACT, the artemisinin derivative causes rapid and effective reduction of parasite biomass and gametocyte carriage, while the partner drug, which has an extended duration of activity, achieves effective clinical and parasitological cure. However, the clinical failures, or at least

\section{Biomed Central}

(c) 2011 Fall et al; licensee BioMed Central Ltd. This is an Open Access article distributed under the terms of the Creative Commons Attribution License (http://creativecommons.org/licenses/by/2.0), which permits unrestricted use, distribution, and reproduction in any medium, provided the original work is properly cited. 
the extended parasite clearance times associated with ACT have been described in Cambodia [4-7]. In addition, prior therapy with ACT containing amodiaquine has selected for P. falciparum isolates with reduced response to monodesethylamodiaquine, thereby suggesting that amodiaquine-containing regimens may have rapidly reduced efficacy in Africa [8].

Dakar, the capital city of Senegal, has an urban population of approximately 1.1 million and a suburban population of 2.3 million; the city covers the majority of the Cap-Vert Peninsular. Malaria is transmitted in Dakar and its surrounding suburbs, with a human biting rate ranging from 0.1 to 43.7 bites per person per night, according to different districts and entomological inoculation rates (EIR) ranging from 0 to 16.8 infected bites per person per year $[9,10]$. Malaria transmission rates are associated with environmental factors, such as vegetation and built-up area [11]. Malaria accounted for $25.9 \%$ of the total cases observed in the Infectious Disease Clinic in Dakar between 2001 and 2003. Of those cases, $65.6 \%$ presented as severe forms [12]. In 2004, malaria attacks accounted for $13.7 \%$ (2977 cases) of all consultations at the Dispensaire St Martin in Dakar, which increased from October to December [13].

Since 2002, ACT has been routinely and widely used in Senegal for managing uncomplicated malaria. ACT is delivered free-of-charge in health centres. Together, artemether-lumefantrine and artesunate-amodiaquine were the ACT recommended as the first-line anti-malarial regimen since it became available in the public system in 2006. Since then, more than 1.5 million treatments have been administered [14]. In 2002-2003, an open randomized study with the drug Artequin ${ }^{\circledR}$ (artesunate-mefloquine) showed an excellent clinical and parasitological response rate of $100 \%$ on day 28 [15]. In 2008, in Kaolack (200 km south-east of Dakar), a study showed that Artequin was efficacious in paediatric patients with a cure rate of $96.2 \%$ in intention-to-treat analysis and was as well tolerated as artemether-lumefantrine [16]. Artesunate-amodiaquine associated cure rates were $>99.3 \%$ in Mlomp and Keur-Socé when administered either as a single daily intake or two daily intakes [17]. The fixed-dose combination of artesunateamodiaquine (ASAQ) shows a cure rate > 98.5\% [18]. The cure rates were $100 \%$ in both populations experiencing a second and third episode of uncomplicated malaria following treatment with ASAQ [14].

Since the introduction of ACT in Senegal, there have been very few reports on the ex vivo susceptibility of $P$. falciparum to anti-malarial drugs. To examine whether parasite susceptibility has been affected by the widespread use of ACT, an ex vivo susceptibility study was conducted with local isolates obtained at the military hospital of Dakar. The new term 'ex vivo susceptibility' is used to describe studies on fresh isolates, while the term 'in vitro susceptibility' should now refer to studies on strains of the parasite, which have been either kept in culture for at least two to three generations or which have been cryo-preserved. The malaria isolates obtained from patients at the Hôpital Principal de Dakar were assessed for susceptibility to chloroquine (CQ), quinine $(\mathrm{QN})$, monodesethylamodiaquine (MDAQ), the active metabolite of amodiaquine, mefloquine (MQ), lumefantrine (LMF), dihydroartemisinin (DHA), the active metabolite of artemisinin derivatives and doxycycline (DOX).

\section{Methods}

\section{Plasmodium falciparum isolates}

In total, 188 patients with malaria were recruited from 14 October 2009 to 19 January 2010 at the Hôpital Principal de Dakar. Venous blood samples were collected in Vacutainer ${ }^{\circledR}$ ACD tubes (Becton Dickinson, Rutherford, NJ, USA) prior to patient treatment; blood samples were used to test drug susceptibility within less than 12 hours (h) of collection. Informed verbal consent was obtained from patients and/or their parents before blood collection. Susceptibility tests were performed on the same blood samples used for malaria diagnosis. The study was reviewed and approved by the ethical committee of Hôpital Principal de Dakar.

Thin blood smears were stained using a $\mathrm{RAL}^{\circledR}$ kit (Réactifs RAL, Paris, France) and were examined to determine $P$. falciparum density and to confirm monoinfection. Parasitized erythrocytes were washed three times in RPMI 1640 medium (Invitrogen, Paisley, UK) buffered with $25 \mathrm{mM}$ HEPES and $25 \mathrm{mM} \mathrm{NaHCO}_{3}$. If parasitaemia exceeded $0.8 \%$, infected erythrocytes were diluted to $0.4 \%$ with uninfected erythrocytes (human blood type $\mathrm{A}+$ ) and re-suspended in RPMI 1640 medium supplemented with $10 \%$ human serum (Abcys S.A. Paris, France), for a final haematocrit of $1.5 \%$.

\section{Drugs}

CQ, QN, DHA and DOX were purchased from Sigma (Saint Louis, MO, USA). MDAQ was obtained from the World Health Organization (Geneva, Switzerland), MQ was purchased from Roche (Paris, France) and LMF was purchased from Novartis Pharma (Basel, Switzerland). $\mathrm{QN}, \mathrm{MDAQ}, \mathrm{MQ}, \mathrm{DHA}$ and DOX were dissolved first in methanol and then diluted in water to final concentrations ranging from $5 \mathrm{nM}$ to $3200 \mathrm{nM}$ for QN, 1.56 $\mathrm{nM}$ to $1000 \mathrm{nM}$ for MDAQ, $3.2 \mathrm{nM}$ to $400 \mathrm{nM}$ for MQ, $0.1 \mathrm{nM}$ to $100 \mathrm{nM}$ for DHA and $0.1 \mu \mathrm{M}$ to 502 $\mu \mathrm{M}$ for DOX. CQ was re-suspended and diluted in water to final concentrations ranging from $5 \mathrm{nM}$ to $3200 \mathrm{nM}$. LMF was re-suspended and diluted in ethanol to obtain final concentrations ranging from $0.5 \mathrm{nM}$ to $310 \mathrm{nM}$. 
The batches of plates were tested and validated on the CQ-susceptible 3D7 strain (West-Africa) and the CQresistant W2 strain (Indochina) (MR4, Virginia, USA) in 3 to 6 independent experiments using both the standard 42-h ${ }^{3} \mathrm{H}$-hypoxanthine uptake inhibition method [19] in controlled atmospheric conditions in an incubator (5\% $\mathrm{CO}_{2}, 10 \% \mathrm{O}_{2}$ and $85 \% \mathrm{~N}_{2}$ ) and the Plasmodium lactate dehydrogenase (pLDH) ELISA [20,21] with the same conditions described in the paragraph below. The two strains were synchronized twice with sorbitol before use [22], and clonality was verified every 15 days using PCR genotyping of the polymorphic genetic markers $m s p 1$ and $m s p 2$ and using microsatellite loci $[23,24]$ and each year by an independent laboratory from the Worldwide Anti-malarial Resistance Network (WWARN).

\section{Ex vivo assay}

For the in vitro isotopic microtests, $200 \mu \mathrm{l}$ of synchronous parasitized red blood cells (final parasitaemia, $0.5 \%$; final haematocrit, $1.5 \%$ ) was aliquoted into 96-well plates pre-dosed with anti-malarial drugs. The plates were incubated in a sealed bag for $42 \mathrm{~h}$ at $37^{\circ} \mathrm{C}$ with the atmospheric generators for capnophilic bacteria Genbag $\mathrm{CO} 2{ }^{\circledR}$ at $5 \% \mathrm{CO}_{2}$ and $15 \% \mathrm{O}_{2}$ (BioMérieux; Marcy l'Etoile, France) [25]. After thawing the plates, haemolysed cultures were homogenized by vortexing the plates. Both the success of the drug susceptibility assay and the appropriate volume of haemolysed culture to use for each assay were determined for each clinical isolate during a preliminary pLDH ELISA. This pre-test and the subsequent ELISAs were performed using the commercial kit (ELISA-Malaria antigen test, ref 750101, DiaMed AG, Cressier s/Morat, Switzerland) as previously described [20]. The optical density (OD) of each sample was measured with a spectrophotometer (Multiskan EX, Thermo Scientific, Vantaa, Finland).

The concentration at which the drugs were able to inhibit $50 \%$ of parasite growth $\left(\mathrm{IC}_{50}\right)$ was calculated with the inhibitory sigmoid Emax model with estimation of the $\mathrm{IC}_{50}$ through non-linear regression using a standard function of the $\mathrm{R}$ software (ICEstimator version 1.2) [26]. $\mathrm{IC}_{50}$ values were validated only if the $\mathrm{OD}$ ratio (OD at concentration 0/OD at concentration max) was superior to 1.8 and the confidence interval ratio (upper $95 \%$ confidence interval of the $\mathrm{IC}_{50}$ estimation/lower $95 \%$ confidence interval of the $\mathrm{IC}_{50}$ estimation) was inferior to 2.0 [26].

\section{Statistical analysis}

$\mathrm{IC}_{50}$ values were analysed after logarithmic transformation and expressed as the geometric mean of the $\mathrm{IC}_{50}$ and the confidence interval 95\% (CI95\%). Assessment of cross-resistance between the seven anti-malarial drugs was measured by pair-wise correlation of $\mathrm{IC}_{50}$ values of all isolates and estimated by the Pearson coefficient of correlation $(r)$ and the coefficient of determination $\left(r^{2}\right)$. The cut-off values for in vitro resistance, or reduced susceptibility, were re-evaluated under experimental conditions induced by the use of the atmospheric generators for capnophilic bacteria Genbag $\mathrm{CO} 2$ by regression. This experiment was performed to compare the prevalence of isolates with in vitro resistance, or reduced susceptibility, tested in Genbag conditions [25] with the prevalence of isolates using the standard $42-\mathrm{h}{ }^{3} \mathrm{H}$ hypoxanthine uptake inhibition method in controlled atmospheric conditions in the incubator $\left(5 \% \mathrm{CO}_{2}, 10 \%\right.$ $\mathrm{O}_{2}$ and $85 \% \mathrm{~N}_{2}$ ) [19] with a cut-off concentration of $100 \mathrm{nM}, 80 \mathrm{nM}, 150 \mathrm{nM}, 10.5 \mathrm{nM}, 800 \mathrm{nM}, 30 \mathrm{nM}$ and $35 \mu \mathrm{M}$ for CQ, MDAQ, LMF, DHA, QN, MQ and DOX, respectively. Using the Plasmodium lactate dehydrogenase (pLDH) ELISA in Genbag conditions, the values were $77 \mathrm{nM}, 61 \mathrm{nM}, 115 \mathrm{nM}, 12 \mathrm{nM}, 611 \mathrm{nM}$, $30 \mathrm{nM}$ and $37 \mu \mathrm{M}$ for CQ, MDAQ, LMF, DHA, QN, $\mathrm{MQ}$ and DOX, respectively. $\mathrm{An} \mathrm{IC}_{50}$ ratio $\left(\mathrm{IC}_{50}\right.$ of clinical isolate/mean $\mathrm{IC}_{50}$ of $3 \mathrm{D} 7$ on the same batch of plates tested in 3 to 6 independent experiments) was calculated for each anti-malarial drug and each isolate in accordance with the guidelines of the WWARN. These ratios were also analysed after logarithmic transformation and expressed as the geometric mean of the ratios and the confidence interval 95\% (CI95\%). 3D7 ratio cut-offs were estimated for in vitro resistance or reduced susceptibility by calculating the ratio of standard threshold at Genbag $\mathrm{CO} 2{ }^{\circledR}$ conditions/3D7 $\mathrm{IC}_{50}$ mean. These values were $5(\mathrm{CQ}), 3$ (MDAQ), 5 (LMF), 7 (DHA), $5(\mathrm{QN}), 0.6(\mathrm{MQ})$ and 3 (DOX).

\section{Consent}

The study was reviewed and approved by the ethics commission of Hôpital Principal de Dakar.

\section{Results}

One hundred and eighty eight patients were recruited for the study at the Hôpital Principal de Dakar; 147 isolates from these patients were tested ex vivo, and 93 isolates were successfully cultured. After validating the $\mathrm{IC}_{50}$ $[(\mathrm{OD}$ at concentration $=0 / \mathrm{OD}$ at concentration $\max )>$ 1.8 and (upper 95\% confidence interval/lower 95\% confidence interval) $<2.0$ ], the following proportion of validated $\mathrm{IC}_{50}$ values were 83 for $\mathrm{CQ}, 83$ for MDAQ, 70 for LMF, 88 for DHA, 82 for QN, 88 for MQ and 76 for DOX.

The average parameter estimates for the seven antimalarial drugs utilized against the $P$. falciparum isolates are given in Table 1. The prevalence of $P$. falciparum isolates with in vitro decreased susceptibility to MQ reached $55 \%$ (Table 2). Only $22 \%$ of the isolates were resistant to CQ. The percent of resistant isolates, or 
Table 1 Ex vivo susceptibility of 93 Plasmodium falciparum isolates from Dakar to chloroquine (CQ), monodesethylamodiaquine (MDAQ), lumefantrine (LMF), dihydroartemisinin (DHA), quinine (QN), mefloquine (MQ) and doxycycline (DOX)

\begin{tabular}{|c|c|c|c|c|c|c|c|c|c|}
\hline \multirow[b]{2}{*}{ Drug } & \multirow[b]{2}{*}{ No } & \multicolumn{4}{|c|}{ Isolate IC $^{50}$} & \multicolumn{4}{|c|}{ Ratio (Isolate IC ${ }^{50} /$ Mean 3D7 IC ${ }^{50}$ ) } \\
\hline & & Mean & $\mathrm{Cl} 95 \%$ & Min & Max & Mean & $\mathrm{Cl} 195 \%$ & Min & Max \\
\hline CQ & 83 & $34.8 \mathrm{nM}$ & $26.9-45.0$ & 4.6 & 1324 & 2.1 & $1.6-2.7$ & 0.26 & 81.7 \\
\hline MDAQ & 83 & $15.7 \mathrm{nM}$ & $12.8-19.4$ & 1.5 & 82.8 & 0.8 & $1.6-2.7$ & 0.07 & 3.9 \\
\hline LMF & 79 & $21.3 \mathrm{nM}$ & $17.1-26.6$ & 1.5 & 150 & 0.8 & $0.6-1.0$ & 0.05 & 5.8 \\
\hline $\mathrm{DHA}$ & 88 & $1.6 \mathrm{nM}$ & $1.3-1.8$ & 0.1 & 9.4 & 0.9 & $0.7-1.0$ & 0.05 & 7.3 \\
\hline QN & 82 & $159 \mathrm{nM}$ & $128-197$ & 6.4 & 1291 & 1.2 & $1.0-1.5$ & 0.06 & 8.6 \\
\hline MQ & 88 & $29.8 \mathrm{nM}$ & $24.3-36.5$ & 3.0 & 170 & 0.5 & $0.4-0.7$ & 0.05 & 3.0 \\
\hline DOX & 76 & $11.6 \mu \mathrm{M}$ & $9.5-14.2$ & 0.5 & 48.1 & 1.1 & $0.9-1.4$ & 0.04 & 4.7 \\
\hline
\end{tabular}

Mean: geometric mean

C195\%: 95\% confidence interval

those with decreased susceptibility, were similar using the 3D7 ratio cut-offs.

The highest significant positive correlations were shown between responses to CQ and MDAQ $(r=0.569$; $P<0.0001)$, LMF and QN $(r=0.511 ; P<0.0001)$, LMF and DHA $(r=0.428 ; P=0.0001)$, LMF and MQ $(r=$ $0.413 ; P=0.0002)$, QN and DHA $(r=0.402 ; P=0.0003)$ and QN and MQ $(r=0.421 ; P=0.0001)$ (Table 3$)$.

\section{Conclusions}

This report describes the evaluation of the ex vivo susceptibility of $P$. falciparum isolates taken from patients in Dakar to seven standard anti-malarial drugs. Analysis of the in vitro susceptibility of $P$. falciparum isolates has three important attributes [27]. First, this approach allows one to assay the response of clinical isolates to individual drugs that remain intact and unmodified by important host factors that influence drug efficacy in vivo. Second, the progressive decline in drug susceptibility of isolates from the same site may identify incipient resistance in the parasite population. Finally, strains with reduced susceptibilities to anti-malarial drugs can be established in continuous culture, thus providing the material needed to investigate novel molecular mechanisms of resistance. These cultures can also provide material for tests of susceptibility to other anti-malarial agents.

This study represents the first use of the 3D7 ratio to address the requirement of the in vitro module of WWARN. The use of this 3D7 ratio could allow for the minimization of bias induced by $\mathrm{IC}_{50}$ variations, which can be caused by plate batches, atmospheric conditions and varying methodologies in general. The 3D7 ratio could allow researchers to compare data and monitor the spatial and temporal evolution of resistance to antimalarial drugs. However, the estimation of the 3D7 ratio cut-off for in vitro resistance or reduced susceptibility must be refined by using a large series of $3 \mathrm{D} 7 \mathrm{IC}_{50}$. Nevertheless, the results in terms of prevalence of resistance are relatively similar between the two estimations.

Previous ex vivo studies in Dakar and in the Fatick region (Dielmo and Ndiop, $280 \mathrm{~km}$ south-east of Dakar) were conducted using the same methodology $\left(42-\mathrm{h}{ }^{3} \mathrm{H}-\right.$ hypoxanthine uptake inhibition method in controlled atmospheric conditions $5 \% \quad \mathrm{CO}_{2}$ and $10 \% \quad \mathrm{O}_{2}$ ) [24,28-35], while certain conditions varied from that in the present study (atmospheric generators for capnophilic bacteria Genbag $\mathrm{CO} 2^{\circledR}$ at $5 \% \mathrm{CO}_{2}$ and $15 \% \mathrm{O}_{2}$ and pLDH ELISA). However, the re-evaluation of the cut-off values for in vitro resistance or reduced susceptibility in

Table 2 Prevalence of in vitro resistant Plasmodium falciparum isolates from Dakar or with reduced susceptibility to chloroquine (CQ), monodesethylamodiaquine (MDAQ), lumefantrine (LMF), dihydroartemisinin (DHA), quinine (QN), mefloquine (MQ) and doxycycline (DOX)

\begin{tabular}{|c|c|c|c|c|c|c|}
\hline \multirow[t]{2}{*}{ Drug } & \multicolumn{3}{|c|}{ Resistant or reduced susceptible isolate IC $^{50}$} & \multicolumn{3}{|c|}{ Resistant or reduced susceptible Ratio (isolate $\mathrm{IC}^{50} / 3 \mathrm{D} 7 \mathrm{IC}^{50}$ ) } \\
\hline & Cut-off & No & $\%$ & Cut-off & No & $\%$ \\
\hline CQ & $77 \mathrm{nM}$ & $18 / 83$ & 22 & 5 & $18 / 83$ & 22 \\
\hline MDAQ & $61 \mathrm{nM}$ & $5 / 83$ & 6 & 3 & $5 / 83$ & 6 \\
\hline LMF & $115 \mathrm{nM}$ & $3 / 79$ & 4 & 5 & $1 / 79$ & 1 \\
\hline DHA & $12 \mathrm{nM}$ & $0 / 88$ & 0 & 7 & $1 / 88$ & 1 \\
\hline QN & $611 \mathrm{nM}$ & $9 / 82$ & 11 & 5 & $5 / 82$ & 6 \\
\hline MQ & $30 \mathrm{nM}$ & $48 / 88$ & 55 & 0.6 & $44 / 88$ & 50 \\
\hline DOX & $37 \mu \mathrm{M}$ & $6 / 76$ & 8 & 3 & 9/76 & 12 \\
\hline
\end{tabular}


Table 3 Correlation of in vitro responses $\left(\log \mathrm{IC}_{50}\right)$ of 93 isolates of Plasmodium falciparum from Dakar to chloroquine (CQ), monodesethylamodiaquine (MDAQ), lumefantrine (LMF), dihydroartemisinin (DHA), quinine (QN), mefloquine (MQ) and doxycycline (DOX)

\begin{tabular}{|c|c|c|c|c|c|c|c|c|}
\hline & & $\mathrm{CQ}$ & MDAQ & LMF & DHA & QN & MQ & DOX \\
\hline \multirow[t]{2}{*}{ MDAQ } & $r$ & 0.569 & 1 & & & & & \\
\hline & p-value & $<0.0001$ & & & & & & \\
\hline \multirow[t]{2}{*}{ LMF } & r & 0.071 & 0.004 & 1 & & & & \\
\hline & p-value & 0.5371 & 0.9732 & & & & & \\
\hline \multirow[t]{2}{*}{$\mathrm{DHA}$} & r & 0.044 & 0.307 & 0.428 & 1 & & & \\
\hline & p-value & 0.7038 & 0.0065 & $<0.0001$ & & & & \\
\hline \multirow[t]{2}{*}{ QN } & r & 0.205 & 0.439 & 0.511 & 0.402 & 1 & & \\
\hline & p-value & 0.0670 & $<0.0001$ & $<0.0001$ & 0.0003 & & & \\
\hline \multirow[t]{2}{*}{$M Q$} & r & 0.267 & 0.412 & 0.413 & 0.357 & 0.421 & 1 & \\
\hline & $p$-value & 0.0180 & 0.0002 & 0.0002 & 0.0008 & 0.0001 & & \\
\hline \multirow[t]{2}{*}{ DOX } & r & 0.313 & 0.025 & 0.306 & 0.249 & 0.318 & 0.390 & 1 \\
\hline & p-value & 0.0105 & 0.8438 & 0.0157 & 0.0347 & 0.0104 & 0.0007 & \\
\hline
\end{tabular}

these new experimental conditions induced by the use of the atmospheric generators for capnophilic bacteria Genbag $\mathrm{CO} 2{ }^{\circledR}$ allows for the comparison of these data with previous data assessed by the standard $42-\mathrm{h}{ }^{3} \mathrm{H}$ hypoxanthine uptake inhibition method in controlled incubator conditions $\left(5 \% \mathrm{CO}_{2}\right.$ and $\left.10 \% \mathrm{O}_{2}\right)$ [25].

Surprisingly, the prevalence of isolates with reduced susceptibility to MQ reached 50\%. This level has increased since previous studies conducted in Senegal. In Dielmo and Ndiop, the percent of isolates with decreased susceptibility was 22\% in 1995 [28] and 15\% in 1999 [33,35]. In Dakar, it was 17\% in 2001 [36] and $13 \%$ in 2002 [24]. Prophylaxis failure with MQ has been previously described in Senegal [37]. MQ is one of the three anti-malarial drugs recommended for travellers as an anti-malarial prophylaxis in Senegal. Clinical trials are in progress to evaluate the efficacy of MQ for intermittent preventive treatment for infants and during pregnancy, while MQ is still used for the treatment of uncomplicated malaria in infants in Dakar. Nevertheless, MQ has been employed relatively infrequently in Africa as compared to Asia. The combination artesunatemefloquine, which is administered to patients in Asia, is not yet used in Senegal. However, scientific data are not available for MQ monotherapy. A positive correlation was shown between MQ and QN $\left(r=0.421 ; r^{2}=0.178\right)$ and between the responses to the components of the ACT used in Dakar, LMF $\left(r=0.413 ; r^{2}=0.171\right)$, MDAQ $\left(r=0.412 ; r^{2}=0.170\right)$ and DHA $\left(r=0.402 ; r^{2}=\right.$ $0.161)$. However, to suggest common mechanisms of action or resistance for two compounds that could induce cross-resistance, the coefficient of determination must be high. A coefficient of determination of 0.161 , $0.170,0.171$ and 0.178 means that only $16.1 \%, 17.0 \%$, $17.1 \%$ and $17.8 \%$ of the variation in the response to MQ is explained by the variation in the response to DHA,
MDAQ, LMF and QN, respectively. The $\mathrm{IC}_{50}$ value of the isolate with the highest DHA $\mathrm{IC}_{50}(9.37 \mathrm{nM})$ was $3.22 \mathrm{nM}$ for MQ. Meanwhile, the $\mathrm{IC}_{50}$ value of the isolate with the highest MQ $\mathrm{IC}_{50}(170 \mathrm{nM})$ was $1.63 \mathrm{nM}$ for DHA. Very few data are available on the in vitro decreased susceptibility to MQ and its clinical implications in Africa. It is important to monitor the evolution of $P$. falciparum susceptibility to $\mathrm{MQ}$, to archive suspicious isolates and to correlate clinical outcomes with pharmacokinetic and phenotypic responses and with molecular markers.

As far back as 1988, in vitro $P$. falciparum resistance to CQ was reported in Dakar, and reports of resistance in other regions of the country followed shortly [38]. From 1991 to 1995, parasitological failures were observed in $21 \%$ of patients in Pikine and in $23 \%$ of patients in another region of Senegal [39]. The in vitro resistance to CQ increased from 1995 to 1999 in Dielmo with $32 \%$ resistance in 1995 [29] as compared to $49 \%$ resistance in 1996 [30], 44\% resistance in 1997 [34] and $55 \%$ resistance in 1999 [33]. Certain single nucleotide polymorphisms (SNPs), such as the $P$. falciparum chloroquine resistance transporter gene $(p f c r t)$ polymorphism K76T, are associated with decreased susceptibility to CQ. Furthermore, this decreased susceptibility to CQ in Dielmo was confirmed by evaluation of the K76T mutation [40]. In Dielmo, the incidence of clinical malaria for patients within seven days of CQ treatment increased from $2.6 \%$ in 1995 to $13 \%$ in 1999 , despite strictly controlled anti-malarial use [40]. A similar increase in in vitro resistance was seen in Dakar and the suburb of Pikine with a prevalence of $30 \%$ to $31 \%$ of strains being resistant to CQ in $2000[41,42]$ increasing to $52 \%$ after $2002[24,43]$. The prevalence of the K76T mutation, which is associated with CQ resistance, was greater than $50 \%$ in both 2001 [41,43] and 2002 [24]. In 2009, in 
Dakar, only $22 \%$ of isolates were found to be resistant $e x$ vivo to CQ. These data are consistent with the work of Ndiaye et al., who showed that $23 \%$ of parasites were resistant to CQ in 2007 in Thies $(75 \mathrm{~km}$ south-east of Dakar) [44]. This decrease in CQ resistance parallels the withdrawal of CQ drug treatment and the introduction of ACT in 2002 in Senegal. However, in 2003, CQ was still being administered to patients. CQ was found in the urine samples of two nine-year-old children, with a prevalence ranging from $14.5 \%$ to $47.5 \%$ in children from north Senegal and from $9.0 \%$ to $21.4 \%$ in children from south Senegal [45]. In 2006, Senegal reported 10.6\% CQ use and 9.7\% ACT use [46]. Since 2006, more than 1.5 million ACT treatments have been administered in Senegal [14]. A similar reduction in CQ resistance was reported in Malawi after withdrawal of CQ treatment [47]. This observation prompted a CQ in vivo study in Malawi five years later, in which CQ was found to be $99 \%$ effective [48]. The rapid dissemination of CQ resistance in Dielmo, despite strictly controlled antimalarial drug use, argues against the re-introduction of $\mathrm{CQ}$ in places where the resistant allele has dropped to very low levels following discontinuation of CQ treatment [40].

Encouragingly, only 6\% of isolates show in vitro reduced susceptibility to MDAQ. This rate is stable with 0\% resistance in 1996 and 1999 in Dielmo [29,35] and $5 \%$ in Mlomp (Casamance, south-western Senegal) in 2004 [49]. The rates remained low even after the introduction of artesunate-amodiaquine in 2002 in Senegal. A positive correlation was shown between MDAQ and CQ responses $\left(r=0.569 ; r^{2}=0.324\right)$, which means that $32.4 \%$ of the variation in the response to MDAQ is explained by variation in the response to CQ. A study in Dakar and Mlomp from 1996 to 1998 showed that monotherapy with amodiaquine remained effective for treating uncomplicated malaria in areas where CQ resistance was prevalent [50].

Only one isolate exhibited reduced susceptibility to DHA. This result is consistent with previous studies that did not show any parasites resistant to artesunate $[24,33,35]$. However, Agnamey et al. reported that 3\% $23 \%$ of isolates had $\mathrm{IC}_{50}$ values greater than $15 \mathrm{nM}$ in Mlomp between 2000 and 2004 [50]. High $\mathrm{IC}_{50}$ values can also be found for artemisinin with $\mathrm{IC}_{50}>30 \mathrm{nM}$ in Dakar [44] and artesunate with $\mathrm{IC}_{50}>45 \mathrm{nM}$ [38].

The other ACT first-line treatment for uncomplicated P. falciparum malaria in Senegal is the combination of artemether-lumefantrine. Only $1 \%$ of the isolates presented reduced susceptibility to LMF. This prevalence did not rise in Senegal after the introduction of ACT. In 1996, 6\% of isolates from Dielmo were resistant in vitro to LMF [31].
Six percent of isolates showed reduced susceptibility to $\mathrm{QN}$, which is in accordance with previous studies in Dakar $[24,36]$ and Dielmo [28,33,35]. Isolates with high $\mathrm{IC}_{50}$ to QN were already identified in 1984 [51]. However, a QN clinical failure was reported in a patient who spent two months in Dielmo in 2007 [52]. QN is often associated with DOX in the treatment of severe malaria in Dakar.

A prevalence of $12 \%$ of isolates with in vitro reduced susceptibility to DOX was observed in Dakar in 2009. The mean $\mathrm{IC}_{50}$ was similar to those estimated in Dielmo in 1998 [32,53]. Parasite populations in Senegal were distributed among three groups with low $(4.9 \mu \mathrm{M})$, medium $(7.7 \mu \mathrm{M})$ and high $(17.7 \mu \mathrm{M}) \mathrm{IC}_{50}$ to DOX [53]. The slow activity of DOX in vitro has a delayed effect upon growth and requires prolonged incubation of parasites [32,54]. However, the standard 42 -h test is still used to monitor DOX in vitro susceptibility.

The introduction of ACT in 2002 in Senegal did not induce a decrease in $P$. falciparum susceptibility to individual drug components, such as DHA, MDAQ and LMF. However, prevalence of $P$. falciparum isolates with reduced drug susceptibility increased for both MQ and DOX. Clinical failures with QN have been reported in Senegal. Additionally, isolates with high $\mathrm{IC}_{50}$ values for artemisinin derivatives have been described for Senegal and for clinical failures, or at least delayed parasite clearance times, have been described in Cambodia. For all of these reasons, an intensive surveillance of the in vitro P. falciparum susceptibility to anti-malarial drugs must be conducted in Senegal.

\section{Acknowledgements}

The authors thank Ndeye Fatou Diop and Maurice Gomis for technical support.

This work was supported by the Etat Major des Armées Françaises (grant schema directeur paludisme LR 607).

\section{Author details}

${ }^{1}$ Laboratoire d'étude de la chimiosensibilité du paludisme, Fédération des laboratoires, Hôpital Principal de Dakar, Dakar, Sénégal. ${ }^{2}$ Unité de parasitologie - Unité de recherche sur les maladies infectieuses et transmissibles émergentes - UMR 6236, Institut de recherche biomédicale des armées, Allée du Médecin-colonel Jamot, Parc le Pharo, BP 60109, 13262 Marseille Cedex 7, France. ${ }^{3}$ Service de réanimation médicale, Hôpital Principal de Dakar, Dakar, Sénégal. ${ }^{4}$ Service de pathologie infectieuse, Hôpital Principal de Dakar, Dakar, Sénégal. ${ }^{5}$ Département de médecine interne et spécialités médicales de pathologie tropicale, Hôpital Principal de Dakar, Dakar, Sénégal. 'Service interne d'hépato-gastroentérologie, Hôpital Principal de Dakar, Dakar, Sénégal. ${ }^{7}$ Chefferie, Hôpital Principal de Dakar, Dakar, Sénégal. ${ }^{8}$ Centre National de référence du Paludisme, Marseille, France.

\section{Authors' contributions}

$\mathrm{BF}, \mathrm{SD}, \mathrm{KS}, \mathrm{EB}, \mathrm{YD}, \mathrm{RB}$ and $\mathrm{BP}$ carried out in vitro testing of drug susceptibility and drafted the manuscript. BD, KBF, PSM, FF and BW carried out diagnostic tests, monitored the patients, collected clinical and epidemiological data and drafted the manuscript. BF, CR, RB and BP analysed the data. All authors conceived and designed the study and read and approved the final manuscript. 


\section{Competing interests}

The authors declare that they have no competing interests.

Received: 4 September 2011 Accepted: 20 October 2011

Published: 20 October 2011

\section{References}

1. Le Bras J, Musset L, Clain J: Antimalarial drug resistance. Med Mal Infect 2006, 36:401-405.

2. White NJ: Preventing antimalarial drug resistance through combinations. 2001. Drug Resist Updat 2001, 1:3-9.

3. Eastman RT, Fidock DA: Artemisinin-based combination therapies: a vital tool in efforts to eliminate malaria. Nat Rev Microbiol 2009, 7:864-874.

4. Carrara VI, Zwang J, Ashley EA, Price RN, Stepniewska K, Barends M, Brockman A, Anderson T, McGready R, Phaiphun L, Proux S, van Vugt M, Hutagalung R, Lwin KM, Phyo AP, Preechapornkul P, Imwong M, Pukrittayakamee S, Singhasivanon P, White NJ, Nosten F: Changes in the treatment responses to artesunate-mefloquine on the Northwestern border of Thailand during 13 years of continuous deployment. PlosOne 2009, 4:4451.

5. Dondorp AM, Nosten F, Yi P, Das D, Phyo AP, Tarning J, Lwin KM, Ariey F, Hanpithakpong W, Lee SJ, Ringwald P, Silamut K, Imwrong M, Chotivanish K, Lim P, Herdman T, An SS, Yeung S, Singhasivanon P, Day NPJ, Lindegardh $N$, Socheat $D$, White $N J$ : Artemisinin resistance in Plasmodium falciparum malaria. N Engl I Med 2009, 361:455-467.

6. Noedl H, Se Y, Schaecher K, Smith BL, Socheat D, Fukuda MM: Evidence of artemisinin-resistant malaria in western Cambodia. N Engl J Med 2008, 359:2619-2620.

7. Rogers WO, Sem R, Tero T, Chim P, Lim P, Muth S, Socheat D, Ariey F, Wongsrichanalai $C$ : Failure of artesunate-mefloquine combination therapy for uncomplicated Plasmodium falciparum malaria in southern Cambodia. Malar J 2009, 8:10.

8. Nawaz F, Nsobya SL, Kiggundu M, Joloba M, Rosenthal PJ: Selection of parasites with diminished drug susceptibility by amodiaquine-containing antimalarial regimens in Uganda. J Infect Dis 2009, 200:1650-1657.

9. Pagès F, Texier $G$, Pradines $B$, Gadiaga $L$, Machault $V$, Jarjaval F, Penhoat $K$, Berger F, Trape JF, Rogier C, Sokhna C: Malaria transmission in Dakar: a two-year survey. Malar J 2008, 7:178.

10. Machault V, Gadiaga L, Vignolles C, Jarjaval F, Bouzid S, Sokhna C, Lacaux JP, Trape JF, Rogier C, Pagès F: Highly focused anopheline breeding sites and malaria transmission in Dakar. Malar J 2009, 8:138

11. Machault V, Vignolles C, Pagès F, Gadiaga L, Gaye A, Sokhna C, Trape JF, Lacaux JP, Rogier C: Spatial heterogeneity and temporal evolution of malaria transmission risk in Dakar, Senegal, according to remotely sensed environmental data. Malar J 2010, 9:252

12. Soumaré M, Seydi M, Diop SA, Ba TA, Ndour $C$, Dieng $Y$, Diop BM, Sow PS Place du paludisme dans un service de pathologie infectieuse à Dakar (Sénégal). Med Trop 2008, 68:485-490.

13. Bob NS, Diop BM, Rnaud F, Marrama L, Durand P, Tall A, Ka B, Ekala MT, Bouchier C, Mercereau-Puijalon O, Jambou R: Parasite polymorphism and severe malaria in Dakar (Senegal): a West African urban area. PlosOne 2011, 5:9817.

14. Ndiaye JLA, Faye B, Gueye A, Tine R, Ndiaye D, Tchania C, Ndiaye I, Barry A, Cisse B, Lameyre V, Gaye O: Repeated treatment of recurrent uncomplicated Plasmodium falciparum malaria in Senegal with fixeddose artesunate plus amodiaquine versus fixed-dose artemether plus lumefantrine: a randomized, open-label trial. Malar J 2011, 10:237.

15. Faye B, Ndiaye JL, Ndiaye D, Dieng Y, Faye O, Gaye O: Efficacy and tolerability of four antimalarial combinations in the treatement of uncomplicated Plasmodium falciparum malaria in Senegal. Malar J 2007 6:80.

16. Faye B, Ndiaye JL, Tine R, Sylla K, Gueye A, Colle Lô A, Gaye O: A randomized trial of artesunate mefloquine versus artemether lumefantrine for the treatment of uncomplicated malaria in Senegalese children. Am J Trop Med Hyg 2010, 82:140-144.

17. Ndiaye JL, Faye B, Diouf AM, Kuété T, Cisse M, Seck PA, Brasseur P, SameEkobo A, Lameyre V, Gaye O: Randomized, comparative study of the efficacy and safety of artesunate plus amodiaquine, administered as a single daily intake versus two daily intakes in the treatment of uncomplicated falciparum malaria. Malar J 2008, 7:16
18. Ndiaye JL, Randrianarivelojosia M, Sagara I, Brasseur P, Ndiaye I, Faye B, Randrianasolo L, Ratsimbasoa A, Forlemu D, Ama Moor V, Traore A, Dicko Y, Dara N, Lameyre V, Diallo M, Djimdé A, Same-Ekobo A, Gaye O: Randomized, multicentre assessment of the efficacy and safety of ASAQ - a fixed dose artesunate-amodiaquine combination therapy in the treatment of uncomplicated Plasmodium falciparum malaria. Malar $J$ 2009, 8:125.

19. Pradines B, Hovette P, Fusai T, Atanda HL, Baret E, Cheval P, Mosnier J, Callec A, Cren J, Amalvict R, Gardair JP, Rogier C: Prevalence of in vitro resistance to eleven standard or new antimalarial drugs among Plasmodium falciparum isolates from Pointe-Noire, Republic of the Congo. J Clin Microbiol 2006, 44:2404-2408.

20. Kaddouri H, Nakache S, Houzé S, Mentré F, Le Bras J: Assessment of the drug susceptibility of Plasmodium falciparum clinical isolates from Africa using a Plasmodium lactate dehydrogenase immunodetection assay and an inhibitory maximum effect model for precise measurement of the 50-percent inhibitory concentration. Antimicrob Agents Chemother 2006, 50:3343-3349.

21. Kaddouri H, Djimdé $A$, Dama $S$, Kodio $A$, Tekete $M$, Hubert V, Koné $A$, Maiga H, Yattara O, Fofana B, Sidibe B, Sangaré CPO, Doumbo O, Le Bras J: Baseline in vitro of efficacy of ACT component drug on Plasmodium falciparum clinical isolates from Mali. Int J Parasitol 2008, 38:791-798.

22. Lambros C, Vanderberg JP: Synchronization of Plasmodium falciparum erythrocytic stages in culture. J Parasitol 1979, 65:418-420.

23. Bogreau H, Renaud F, Bouchiba H, Durand P, Assi SB, Henry MC, Garnotel E, Pradines B, Fusai T, Wade B, Adehossi E, Parola P, Kamil MO, Puijalon O, Rogier C: Genetic diversity and structure of African Plasmodium falciparum populations in urban and rural areas. Am J Trop Med Hyg 2006, 74:953-959.

24. Henry M, Diallo I, Bordes J, Ka S, Pradines B, Diatta B, M'Baye PS, Sane M Thiam M, Gueye PM, Wade B, Touze JE, Debonne JM, Rogier C, Fusai T: Urban malaria in Dakar, Senegal: chemosusceptibility and genetic diversity of Plasmodium falciparum isolates. Am J Trop Med Hyg 2006, 75:146-151.

25. Pascual A, Basco LK, Baret E, Amalvict R, Travers D, Rogier C, Pradines B: Use of the atmospheric generators for capnophilic bacteria Genbag $\mathrm{CO}_{2}{ }^{\circledR}$ for the evaluation of in vitro Plasmodium falciparum susceptibility to standard anti-malarial drugs. Malar J 2011, 10:8

26. Le Nagard $H$, Vincent $C$, Mentré $F$, Le Bras J: Online analysis of in vitro resistance to antimalarial drugs through nonlinear regression. Comput Methods Programs Biomed 2010.

27. Bacon DJ, Jambou R, Fandeur T, Le Bras J, Wrongsrichanalai C, Fukuda MM, Ringwald P, Hopkins Sibley C, Kyle DE: World Antimalarial resistance Netwwork (WARN) II: In vitro antimalarial drug susceptibility. Malar J 2007, 6:120.

28. Pradines B, Rogier C, Fusai T, Tall A, Doury JC: Sensibilité in vitro de 85 isolats de Plasmodium falciparum au Sénégal. Med Trop 1996, 56:141-145.

29. Pradines B, Rogier C, Fusai T, Tall A, Trape JF, Doury JC: In vitro activity of artemether against African isolates (Senegal) of Plasmodium falciparum in comparison with standard antimalarial drugs. Am J Trop Med Hyg 1998, 58:354-357.

30. Pradines B, Tall A, Parzy D, Spiegel A, Fusai T, Hienne R, Trape JF, Doury JC: In vitro activity of pyronaridine and amodiaquine against African isolates (Senegal) of Plasmodium falciparum in comparison with standard antimalarial agents. J Antimicrob Chemother 1998, 42:333-339.

31. Pradines B, Tall A, Fusai T, Spiegel A, Hienne R, Rogier C, Trape JF, Le Bras J, Parzy D: In vitro activities of benflumetol against 158 Senegalese isolates of Plasmodium falciparum in comparison with those of standard antimalarial drugs. Antimicrob Agents Chemother 1999, 43:418-420.

32. Pradines B, Spiegel A, Rogier C, Tall A, Mosnier J, Fusai T, Trape JF, Parzy D: Antibiotics for prophylaxis of Plasmodium falciparum infections: in vitro activity of doxycycline against Senegalese isolates. Am J Trop Med Hyg 2000, 62:82-85.

33. Pradines B, Tall A, Rogier C, Spiegel A, Mosnier J, Marrama L, Fusai T, Millet $P$, Panconi $E$, Trape JF, Parzy D: In vitro activities of ferrochloroquine against 55 Senegalese isolates of Plasmodium falciparum in comparison with those of standard antimalarial drugs. Trop Med Int Health 2002, 7:265-270.

34. Pradines B, Tall A, Ramiandrasoa F, Spiegel A, Sokhna C, Fusai T, Mosnier J, Daries W, Trape JF, Kunesch G, Parzy D, Rogier C: In vitro activity of iron- 
binding compounds against Senegalese isolates of Plasmodium falciparum. J Antimicrob Chemother 2006, 57:1093-1099.

35. Pradines B, Mabika Mamfoumbi M, Tall A, Sokhna C, Koeck JL, Fusai T, Mosnier J, Czarnecki E, Spiegel A, Trape JF, Kombila M, Rogier C: In vitro activity of tafenoquine against the asexual blood stages of Plasmodium falciparum isolates from Gabon, Senegal, and Djibouti. Antimicrob Agents Chemother 2006, 50:3225-3226.

36. Jambou R, Legrand E, Niang M, Khim N, Lim P, Volney B, Ekala MT, Bouchier C, Esterre P, Fandeur T, Mercereau-Puijalon O: Resistance of Plasmodium falciparum field isolates to in vitro artemether and point mutations of the SERCA-type PfATPase6. Lancet 2005, 366:1960-1963.

37. Gari-Toussaint M, Pradines B, Mondain V, Keundjian A, Dellamonica P, Le Fichoux Y: Sénégal et paludisme. Echec prophylactique vrai de la méfloquine. Presse Med 2002, 31:1136.

38. Hatin I, Trape JF, Legros F, Bauchet J, Le Bras J: Susceptibility of Plasmodium falciparum strains to mefloquine in an urban area in Senegal. Bull World Health Organ 1992, 70:363-367.

39. Sokhna C, Molez JF, Ndiaye P, Sane B, Trape JF: Tests in vivo de chimiosensibilite de Plasmodium falciparum à la chloroquine au Sénégal: évolution de la résistance et estimation de l'efficacité thérapeutique. Bull Soc Pathol Exot 1997, 90:83-89.

40. Norate N, Durand R, Tall A, Marrama L, Spiegel A, Sokhna C, Pradines B, Cojean S, Guillotte M, Bischoff E, Ekala MT, Bouchier C, Fandeur T, Ariey F, Patarapotikul J, Le Bras J, Trape JF, Rogier C, Mercereau-Puijalon O: Rapid dissemination of Plasmodium falciparum drug resistance despite strictly controlled antimalarial use. PlosOne 2007, 1:139.

41. Dieng T, Bah IB, Ndiaye PM, Diallo I, Diop BM, Brasseur P, Mboup S, Wirth D, Ndir O: Evaluation de la sensibilité in vitro de Plasmodium falciparum à la chloroquine par le Deli-test dans la région de Dakar (Sénégal). Med Trop 2005, 65:580-583.

42. Thomas SM, Ndir O, Dieng T, Mboup S, Wypij D, Maguire JH, Wirth DF: In vitro chloroquine susceptibility and PCR analysis of pfcrt and pfmdr1 polymorphisms in Plasmodium falciparum isolates from Senegal. Am J Trop Med Hyg 2002, 66:474-480.

43. Sarr O, Myrick A, Daily J, Diop BM, Dieng T, Ndir O, Salif Sow P, Mboup S, Wirth DF: In vivo and in vitro analysis of chloroquine resistance in Plasmodium falciparum isolates from Senegal. Parasitol Res 2005, 97:136-140.

44. Ndiaye D, Patel V, Demas A, LeRoux M, Ndir O, Mboup S, Clardy J, Lakshmanan V, Daily JP, Wirth DF: Short report: an non-radioactive DAPIbased high-throughput in vitro assay to assess Plasmodium falciparum responsiveness to antimalarials - Increased sensitivity of $P$. falciparum to chloroquine in Senegal. Am J Trop Med Hyg 2010, 82:228-230.

45. Gardella F, Assi S, Simon F, Bogreau H, Eggelte T, Ba F, Foumane V, Henry MC, Traore Kientega P, Basco L, Trape JF, Lalou R, Martelloni M, Desbordes M, Baragatti M, Briolant S, Almeras L, Pradines B, Fusai T, Rogier $C$ : Antimalarial drug use in general populations of tropical Africa. Malar J 2008, 7:124.

46. Frosch AEP, Venkatesan M, Laufer MK: Patterns of chloroquine use and resistance in sub-Saharan Africa: a systematic review of household survey and molecular data. Malar J 2011, 10:116.

47. Kublin JG, Cortese JF, Njunju EM, Mukadam RA, Wirima JJ, Kazembe PN, Djimdé AA, Kouriba B, Taylor TE, Plowe CV: Remergence of chloroquinesensitive Plasmodium falciparum malaria after cessation of chloroquine in Malawi. J Infect Dis 2003, 187:1870-1875.

48. Laufer MK, Thesing PC, Eddington ND, Masonga R, Dzinjalamala FK, Takala SL, Taylor TE, Plowe CV: Return of chloroquine antimalarial efficacy in Malawi. N Engl J Med 2006, 355:1959-1966.

49. Agnamey P, Brasseur P, Eldin de Pecoulas P, Vaillant M, Olliaro P: Plasmodium falciparum in vitro susceptibility to antimalarial drugs in Casamance (Southwestern Senegal) during the first 5 years of routine use of artesunate-amodiaquine. Antimicrob Agents Chemother 2006, 50:1531-1534.

50. Brasseur P, Guiguemde R, Diallo S, Guiyedi V, Kombila M, Ringwald P, Olliaro P: Amodiaquine remains effective for treating ucomplicated malaria in West and Central Africa. Trans R Soc Trop Med Hyg 1999, 93:645-650

51. Brandicourt O, Druilhe P, Diouf F, Brasseur P, Turk P, Danis M: Decreased sensitivity to chloroquine and quinine of some Plasmodium falciparum strains from Senegal in september 1984. Am J Trop Med Hyg 1986, 35:717-721.
52. Pradines B, Pistone T, Ezzedine K, Briolant S, Bertaux L, Receveur MC Parzy D, Millet $\mathrm{P}$, Rogier C, Malvy D: Quinine-resistant malaria in traveler returning from Senegal, 2007. Emerg Infect Dis 2010, 16:546-548.

53. Briolant S, Baragatti M, Parola P, Simon F, Tall A, Sokhna C, Hovette P, Mabika Mamfoumbi M, Koeck JL, Delmont J, Spiegel A, Castello J, Gardair JP, Trape JF, Kombila M, Minodier P, Fusai T, Rogier C, Pradines B: Multinormal in vitro distribution model suitable for the distribution of Plasmodium falciparum chemosusceptibility to doxycycline. Antimicrob Agents Chemother 2009, 53:688-695.

54. Pradines B, Rogier C, Fusai T, Mosnier J, Daries W, Baret E, Parzy D: In vitro activities of antibiotics against Plasmodium falciparum are inhibited by iron. Antimicrob Agents Chemother 2001, 45:1746-1750.

doi:10.1186/1475-2875-10-310

Cite this article as: Fall et al:. Ex vivo susceptibility of Plasmodium falciparum isolates from Dakar, Senegal, to seven standard anti-malarial drugs. Malaria Journal 2011 10:310.

\section{Submit your next manuscript to BioMed Central and take full advantage of:}

- Convenient online submission

- Thorough peer review

- No space constraints or color figure charges

- Immediate publication on acceptance

- Inclusion in PubMed, CAS, Scopus and Google Scholar

- Research which is freely available for redistribution

Submit your manuscript at www.biomedcentral com/submit
C Biomed Central 